\title{
Supply Chain Investment in Carbon Emission-Reducing Technology Based on Stochasticity and Low-Carbon Preferences
}

\author{
Shan Yu $(\mathbb{D}$ and Qiang Hou \\ School of Management, Shenyang University of Technology, Shenyang 110870, China \\ Correspondence should be addressed to Qiang Hou; 18904046277@163.com
}

Received 19 August 2020; Revised 23 January 2021; Accepted 13 February 2021; Published 23 February 2021

Academic Editor: Charbel Jose Chiappetta Jabbour

Copyright ( 92021 Shan Yu and Qiang Hou. This is an open access article distributed under the Creative Commons Attribution License, which permits unrestricted use, distribution, and reproduction in any medium, provided the original work is properly cited.

\begin{abstract}
Due to excessive greenhouse gas emissions, carbon emission-reducing measures are urgently needed. Important emission-reduction measures mainly include carbon trading and low-carbon cost subsidies. Comprehensive consideration of these two policies is a research hotspot in the field of low-carbon technology investment. Based on this background, this paper considers the impact of consumer low-carbon preferences on market demand and the impact of uncertainty in carbon emission-reduction behaviour. We construct a stochastic differential game model with upstream and downstream enterprises based on cost-sharing coordination under a cost subsidy. From a dynamic perspective, this paper researches the optimal equilibrium strategy and evolution characteristics of the joint emission-reduction mechanism in a supply chain. This paper discusses the sensitivity of the parameters and uses numerical simulation to verify the impact of each parameter on the emission-reduction decision-making activities of stakeholders after introducing the cost subsidy. The results show that a cost subsidy policy can promote carbon emission-reduction investment and supply chain profit. Thus, it is important to strengthen technical cooperation and exchange among enterprises.
\end{abstract}

\section{Introduction}

Low-carbon economy is an inevitable choice for the sustainable development of global economy. Developing low-carbon economy is conducive to breaking through the bottleneck constraints of resources and environment in the process of economic development and taking the new road of industrialization; it is conducive to forming a sound policy mechanism and institutional guarantee system to promote sustainable development; it is conducive to promoting industrial upgrading and technological innovation of enterprises and building the future international core competitiveness of enterprises. It provides a rare opportunity to realize the fundamental transformation of the economic mode. Under the current situation, actively developing circular economy and lowcarbon economy is the best choice to achieve sustainable development. It requires us not only to change the traditional high-carbon economic development mode from the adjustment of industrial structure and energy structure but also to seek energy-saving ways and promote energy-saving technology from all aspects of the industrial chain. As a major developing country and high-carbonemitting country, China is actively exploring various carbon emission-reduction measures. The government actively adjusts the industrial and energy structures from a macroperspective, implements carbon emissions trading, and encourages technological innovation from a microperspective. With the implementation of China's carbon trading system, the carbon trading market's demand for carbon-dependent enterprises has gradually risen. Designing a carbon trading policy that encourages carbondependent enterprises to invest in production and carbon emission-reduction measures has become a focus of social concern. Due to the dynamic and uncertain nature of innovation, carbon emission-reduction behaviour presents high uncertainty. Therefore, it is important to study the influence of the carbon trading system on corporate 
emission reduction based on the perspective of stochastic differential games.

Under the background of carbon emission trading and cost subsidies, and considering the low-carbon preferences of consumers and the randomness of the emission-reduction process, this paper uses a stochastic differential game method to analyse the game relationships between the government, manufacturers, retailers, and consumers under cost-sharing coordination from a dynamic perspective. The equilibrium strategies of government, supply chains, and consumers are obtained, and the evolutionary paths of emission reduction, manufacturer profit, and retailer profit are obtained.

The object of this paper is to (1) calculate an objective function describing carbon emission reduction, manufacturer profit, retailer profit, and cost-sharing ratio; (2) consider the low-carbon preferences of consumers and the randomness of the emission-reduction process and study the optimal equilibrium strategies of the government, supply chains, and consumers under cost subsidies and the evolutionary path of carbon emission reduction and supply chain profit; and (3) explore the sensitivity of cost subsidy rates and other stochastic factors to supply chain emission reductions via a numerical experiment.

The theoretical value of this paper lies in its in-depth exploration of supply chain enterprise cooperation mechanisms and the design of carbon emission-reduction investment paths. It provides a theoretical basis for decisionmaking by supply chain enterprises operating under environmental regulation. The practical significance of this paper is to analyse the optimal decision-making paths of coordinated cost-sharing decision-making under a carbon trading system and cost subsidy policies from a dynamic perspective. This provides theoretical support for technological investment and output decision-making by supply chain enterprises.

The structure of this paper is as follows. Section 2 is a literature review. Section 3 describes the problem in terms of the carbon trading system and emission-reduction technological innovation subsidies under uncertain circumstances of carbon emission-reduction behaviour. A stochastic differential game model is then constructed on this basis. Section 4 uses stochastic differential game theory to solve the Stackelberg equilibrium under a feedback strategy. Section 5 uses the stochastic differential Stackelberg game model to predict emission-reduction inputs and the evolution path of variables. Section 6 provides a parameter sensitivity analysis. Section 7 describes the numerical simulation and the final section makes the conclusions.

\section{Literature Review}

The essence of sustainable development is that supply chain enterprises start from the energy structure and change the traditional mode of high-carbon economy. Swiader evaluated the natural area surface for carbon fiber assimilation and provided management tools and policy tools for the sustainable development of human settlements [1]. Renwick explored the effect of practice in achieving workplace goals of environmental sustainability [2]. Bashir discussed the relationship between environmental taxes and carbon emissions, as well as the role of environmental technology and financial development [3]. Nong put forward suggestions on energy resources, policies, and scientific research to achieve a cleaner and more sustainable economy in Vietnam [4]. Jackson studied the labor, reciprocity, and care logic needed to reduce or sequester carbon through the case of carbon agriculture to reduce carbon emissions [5]. Douglas made a theoretical and conceptual comparative analysis on the policies and measures of coal-dependent employment, determined the measures to successfully improve the social and economic well-being of coal-dependent communities, and put forward the framework to successfully achieve a just transition [6]. Amundson proposed a quantitative risk analysis method of biomass supply chain based on Bayesian belief network (BBN) [7].

The impact of microeconomic policies on enterprises' carbon emission-reduction investment behaviour began with the research of Benjaafar, who studied the impact of joint emission reductions by supply chain members on operating costs and carbon emissions [8]. Song et al. proposed a carbon footprint calculation model based on discriminant factors [9]. Elhedhli and Merrick found that the optimal allocation of a supply chain can be achieved by adjusting the cost of carbon emissions [10]. Dai and $\mathrm{Hu}$ proposed a double-objective network optimization model of a low-carbon closed-loop supply chain [11]. Chen et al. constructed a fuzzy programming optimization model to find the lowest total cost [12]. Lou et al. proposed a Stackelberg game emission-reduction investment model with manufacturers as the leaders and retailers as the followers [13]. Fu et al. obtained the evolutionarily stable strategy for supplier and manufacturer emission-reduction input behaviour [14]. Liu et al. studied the operational decisions of original equipment manufacturers and authorized remanufacturers under the carbon emission quota and trading rules in a two-echelon supply chain [15]. Zhao et al. analysed the joint carbon emission-reduction problem in a secondary supply chain composed of two manufacturers and a dominant retailer [16]. In addition, Yang et al. compared the effects of four low-carbon policies on supply chain coordination [17]. Xu et al. studied the decision-making and coordination of a two-level supply chain composed of manufacturers and retailers [18]. Yang and Wang compared and analysed carbon emission reduction and supply chain profit under the three situations of decentralization, concentration, and revenue-sharing contracts [19]. Xu et al. studied the game coordination of supply chain members under consignment contracts, revenue-sharing contracts, and revenue-sharing and emission-reduction cost-sharing contracts [20].

In addition, the impact of government on supply chain emission-reduction decision-making is crucial. Zhang et al. studied the optimal investment decisions of a supply chain considering a government carbon tax [21]. Kang et al. studied the behaviour of low-carbon supply chain enterprises and strategic issues related to government low-carbon policies and emerging low-carbon markets [22]. Sun et al. 
analysed carbon emission transfer and reduction among enterprises in a supply chain [23]. Wang et al. studied the dynamic coordination of long-term cooperative emission reduction in supply chains under government subsidies [24]. Peng analysed the popular quantity discount contract and revenue-sharing contract in a supply chain [25]. Li et al. discussed the coordination methods of a low-carbon supply chain under different channel power structures [26]. Wang compared differences in levels of emission-reduction effort, advertising, and the present value of supply chain total profit under decentralized and cooperative decision-making modes [27]. Han et al. established a game model to study the decision-making behaviour of manufacturers in a low-carbon e-commerce supply chain that received government carbon subsidies that considered fairness [28]. Wang et al. studied the long-term dynamic cooperative emission reduction and government subsidy strategies of a two-level supply chain [29]. Wang et al. established single and joint emission-reduction models in which supply chain members could adopt one- or two-way cost-sharing contracts and analysed the optimal strategy design and appropriate sharing rate contract [30]. Wang studied the decision-making problem of a two-echelon supply chain composed of a single manufacturer and a single retailer [31]. Zhang et al. discussed the influences of emission-reduction rate, carbon tax, and unit carbon emissions on order quantity, revenue, and contract parameters [32]. Liu and Li established a differential game model of a two-level supply chain and introduced a low-carbon preference into the model. They discussed in detail the impact of low-carbon reference carbon emission reduction by a supply chain [33]. Zhu et al. compared and analysed two situations of government subsidies to lowcarbon product manufacturers and consumers who purchased low-carbon products [34]. Li et al. analysed the interactive game between government subsidies and enterprises' choices of emission-reduction cooperation [35]. Zhao et al. analysed the influence coefficient of different subsidy objects on the pricing decisions and profits of channel members [36]. Wei considered dynamic changes in carbon emissions and constructed a differential game model of emission-reduction investment by a supply chain [37]. Wang et al. studied the joint emission-reduction coordination problem of a three-level supply chain with centralized and decentralized decision-making and cost-sharing collaborative decision-making [38].

The above literature mainly considers the operational cooperation of a low-carbon supply chain from a static perspective. However, enterprise operations often span multiple cycles. Therefore, it is very important to study coordination and cooperation between the upstream and downstream enterprises in a low-carbon supply chain from a dynamic perspective. Mohamad et al. analysed the selection of the best cooperation mode for supply chain management when the carbon emission limit is exceeded [39]. Ren et al. researched the influence of government subsidies on enterprise decision-making behaviour via a two-stage dynamic game [40]. Wang et al. constructed three dynamic game models involving decentralized decision-making without cost-sharing, decentralized decision-making, and centralized decision-making under cost-sharing. They analysed the dynamic strategy of regional low-carbon technology [41]. Huang and Yuan proposed a Stackelberg differential game model of a single government and multiple enterprises in a limited period [42]. Yang et al. constructed a continuous-time dynamic model of differential inequality [43]. Giovanni studied the optimal green advertising investment and pricing strategies of manufacturers and retailers under wholesale-pricing and reverse-revenue-sharing contracts, respectively [44]. Considering a carbon trading market and the low-carbon preferences of consumers, Liu et al. obtained the low-carbon technology conditions required to achieve a win-win situation [45]. Zhao et al. studied the vertical cooperative emission-reduction dynamic optimization problem of a low-carbon supply chain [46]. Ye et al. studied supply chain dynamic optimization and the coordination of joint emission reductions with consideration of consumers' low-carbon preferences [47]. You et al. compared the long-term dynamic equilibrium strategies of a two-level supply chain under decentralized and centralized decision-making situations [48]. Xu et al. constructed and analysed three differential game models: decentralized decision-making without cost-sharing, decentralized decisionmaking under a cost-sharing contract, and centralized decision-making under collaborative control [49].

Existing research has mainly focused on manufacturer research and development (R\&D) investment. The retailers use low-carbon publicity or promotion to follow the manufacturers. However, no research has considered that the emission reductions related to product manufacturing decline naturally over time, which affects the incentive for enterprises to reduce emissions. Therefore, this paper uses the stochastic differential game method to expand the research in this field. Considering a scenario of a carbon trading market with a cost subsidy, this paper comprehensively analyses consumers' low-carbon preferences and random factors in the process of carbon emission reduction. It obtains the optimal equilibrium strategy and evolution path for joint carbon emission reduction by manufacturers and retailers.

\section{Stochastic Differential Game Model}

3.1. Problem Description. Actively developing circular economy and low-carbon economy is the best choice to achieve sustainable development. To develop low-carbon economy, we should not only change the traditional development mode of high-carbon economy but also seek energy-saving ways and promote energy-saving technologies from all aspects of the supply chain. Therefore, this paper considers a carbon emission-reduction system of a simple secondary supply chain composed of a manufacturer and a retailer. Widely used low-carbon supply chain coordination mechanisms include cooperative advertising contracts, revenue-sharing contracts, wholesale price contracts, costsharing contracts, and two-part contracts. This paper studies the cooperation between upstream and downstream enterprises in the practice of carbon emission-reduction supply chain management. The upstream manufacturer carries out 
energy and emission reductions, and the downstream retailer shares certain costs. In general, the manufacturer is the main source of emission reduction and faces more pressure than the retailer. Meanwhile, the manufacturer can transfer the cost of emission reduction downstream through market forces. Therefore, the manufacturer is the decision-maker in the differential game and the retailer follows the manufacturer to share the $\mathrm{R} \& \mathrm{D}$ cost of emission reduction. In China's quota-based carbon trading system, the government grants enterprises a certain carbon quota. Emissions that exceed the quota must be purchased from the society. At the same time, carbon trading is carried out in some large markets and the supply chain has no effect on the carbon price. Therefore, it is assumed that the carbon price is exogenous. In addition, this paper assumes that consumers have a low-carbon preference; i.e., they prefer products associated with lower carbon emissions.

To describe the above problems, this paper defines the parameters shown in Table 1.

This paper simplifies the complex conditions and makes the following hypotheses.

Hypothesis 1 (demand function hypothesis). Referring to the research of Laroche et al. [50] and Ouardighi [51, 52], market demand is mainly affected by price factors and nonprice factors, which affect market demand in the form of separable multiplication. The product demand function is as follows:

$$
Q_{E}(t)=(a-b p(t)) k E(t)
$$

Hypothesis 2 (input cost hypothesis of emission-reduction technology). The manufacturer's emission-reduction cost function is an extension of the hypothesis of the innovation cost function. The function is a convex function describing emission-reduction efforts. Thus, the manufacturer's emission-reduction cost at time $t$ is given by

$$
C\left(Z_{M}(t)\right)=\frac{\mu_{M}}{2} Z_{M}^{2}(t) .
$$

Hypothesis 3 (interest intensity hypothesis). Suppose that the upstream manufacturer and downstream retailer have the same interest intensity $\rho$, and $\rho>0$.

3.2. Dynamic Model of Carbon Emission-Reduction Investment. The supply chain modelled in this paper is a simple two-level supply chain with one manufacturer and one retailer. This paper studies a model of investment in carbon emission-reduction technology based on government subsidies and consumer low-carbon preference. The decision-making process of the government, supply chain, and consumers is shown in Figure 1.

The emission-reduction process is affected by investment in emission-reduction subject, facilities maintenance, consumer environmental awareness, and various uncontrollable factors. Thus, the emission-reduction process is random.

Hypothesis 4. The stochastic process of carbon emission reduction is composed of three driving forces. One is a random factor, which can be described as a standard Wiener process $\mathrm{d} E(t)=\delta \sqrt{E(t)} \mathrm{d} z(t)$, in which $\delta$ is a fluctuation parameter of carbon emission reduction. The second is the carbon emission reduction resulting from $\mathrm{R} \& \mathrm{D}$ investment by the emission-reduction subject $\mathrm{d} E(t)=\alpha Z_{M}(t) \mathrm{d} t$, in which $Z_{M}(t)$ is the emission-reduction effort. The third changes in environmental awareness and equipment ageing, $\mathrm{d} E(t)=-\sigma E(t) \mathrm{d} t$, in which $\sigma$ is the emission-reduction coefficient. The overall dynamic equation is the sum of the three parts:

$$
\mathrm{d} E(t)=\left(\alpha Z_{M}(t)-\sigma E(t)\right) \mathrm{d} t+\delta \sqrt{E(t)} \mathrm{d} z(t) .
$$

\subsection{Objective Function of the Manufacturer and Retailer.} Carbon trading system based on a carbon quota is essentially the intensity control mode. It is assumed that the carbon quota and carbon emissions per unit product set by the government are fixed in a certain period. Thus, the function of the carbon emissions trading cost is as follows:

$$
E_{M T(t)}=p_{e}\left[g_{M} Q_{E}(t)+E(t)-e_{M} Q_{E}(t)\right] .
$$

In actual operations, for a carbon emission-reduction supply chain that is regulated by the government, the profit function of the manufacturers consists of sales revenue, carbon emission-reduction costs, and carbon trading income. Considering that the retailer will share part of the carbon emission-reduction cost of the manufacturer, the retailer's profit function is composed of sales revenue and carbon emission-reduction cost. In addition, the goal of the game between the manufacturer and retailer is to maximize profit. For ease of expression, $t$ is not listed below.

Thus, the objective function of the manufacturers is as follows:

$$
\begin{aligned}
& \max E\left\{J_{M}\left[\omega, Z_{M}, \xi\right]\right\}= \\
& \max E\left\{\int_{0}^{\infty} e^{-\rho t}\left\{(w-c) Q_{E}-(1-\xi)(1-\tau) \frac{\mu_{M}}{2} Z_{M}^{2}+p_{e}\left(g_{M} Q_{E}+E-e_{M} Q_{E}\right)\right\} \mathrm{d} t\right\} .
\end{aligned}
$$


TABLe 1: Description of the parameters of the model.

\begin{tabular}{lc}
\hline Variable & Description \\
\hline$p$ & Product retail price \\
$a$ & Product market size \\
$Q_{E}$ & Quantity demanded considering consumer low-carbon preference \\
$\mu_{m}$ & Abatement cost coefficient \\
$\alpha$ & Impact coefficient of the manufacturer's emission-reduction effort \\
$g_{m}$ & Per unit product emission quota set by government regulations \\
$c$ & Manufacturer's unit production cost \\
$J_{M}$ & Profit of the manufacturer \\
$k$ & Low-carbon sensitivity coefficient of consumers \\
$\tau$ & Cost subsidy coefficient \\
$\delta$ & Fluctuation coefficient of emission reduction \\
$w$ & Manufacturer's wholesale price \\
$b$ & Product marginal demand \\
$Z_{m}$ & Emission-reduction effort \\
$E$ & Carbon emission reduction \\
$\sigma$ & Carbon emissions per unit product without emission-reduction investment \\
$e_{m}$ & Discount rate \\
$\rho$ & Profit of the retailer \\
$J_{R}$ & Carbon trading price \\
$\xi$ &
\end{tabular}

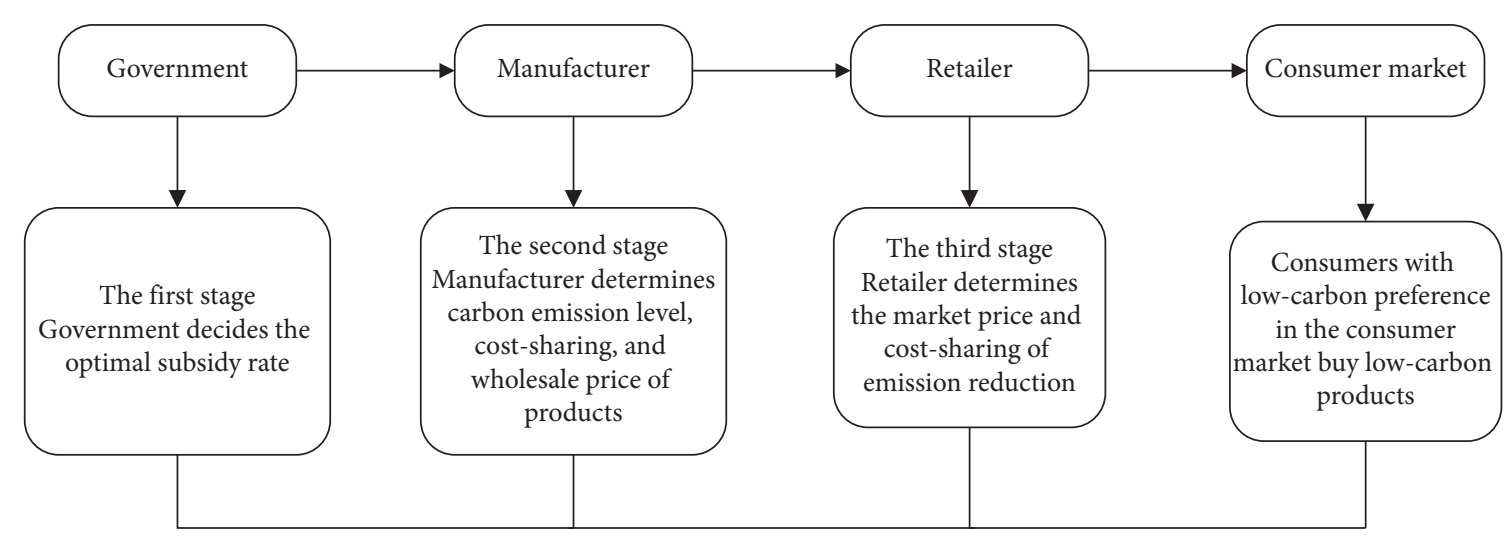

Figure 1: Decision diagram.

The objective function of the retailers is as follows:

$$
\max E\left\{J_{R}[p, \xi]\right\}=\max E\left\{\int_{0}^{\infty} e^{-\rho t}\left\{(p-w) Q_{E}-\xi(1-\tau) \frac{\mu_{M}}{2} Z_{M}^{2}\right\} \mathrm{d} t\right\}
$$

3.4. Stochastic Differential Game Model. Assuming that the government, manufacturers, and retailers adopt a progressive Stackelberg game, the stochastic differential game model of the carbon emission system is as follows:

$$
\text { s.t. }\left\{\begin{array}{l}
\max _{\omega, Z_{M}, \xi} J_{M}\left(w, Z_{M}, \xi ; p\right), \\
\max _{p, \xi} J_{R}\left(w, Z_{M}, \xi ; p\right) ; \\
\mathrm{d} E(t)=\left(\alpha Z_{M}(t)-\sigma E(t)\right) \mathrm{d} t+\delta \sqrt{E(t)} \mathrm{d} z(t), \\
E(0)=E_{0} .
\end{array}\right.
$$

\section{Equilibrium Strategy}

Based on the stochastic differential game method, this paper discusses the game process between upstream and downstream enterprises of a supply chain and obtains the feedback equilibrium between the manufacturer and the retailer. Firstly, the manufacturer determines the wholesale price and carbon emission-reduction efforts of the products at each moment and carries out a game with the retailer to determine the cost-sharing proportion. Secondly, the retailer determines the market price of products at each moment and carries out a game with the manufacturer to determine the emission-reduction cost-sharing ratio. 
Theorem 1. The decision-making goal of upstream manufacturers and downstream retailers is to maximize their respective profits. The game equilibrium results of the manufacturer and retailer are as follows:

$$
\begin{aligned}
w^{*} & =\frac{1}{2 b}\left(a+b c+b p_{e} e_{M}-b p_{e} g_{M}\right), \\
Z_{M}^{*} & =\frac{V_{M}^{S}}{(1-\xi)(1-\tau)} \frac{\alpha}{\mu_{M}}, \\
p^{*} & =\frac{1}{4 b}\left(3 a+b c+b p_{e} e_{M}-b p_{e} g_{M}\right), \\
\xi & =\frac{2 V_{R}^{S}-V_{M}^{S}}{2 V_{R}^{S}+V_{M}^{S}} .
\end{aligned}
$$

Proof. It is assumed that the wholesale price of manufacturer $\omega(t)$ and the carbon emission-reduction effort $Z_{M}(t)$ are given for any time $t \in[0, \infty)$. This paper uses backward induction and continuous-time dynamic programming theory to obtain the HJB equation. The HJB equation satisfies the retailer's optimal product pricing and optimal costsharing ratio.

$$
\rho V_{R}^{S}=\max _{p, \xi}\left\{(p-w)(a-b p) k E-\xi \frac{\mu_{M}(1-\tau)}{2} Z_{M}^{2}+V_{R}^{S}\left(\alpha Z_{M}-\sigma E\right)\right\}+\frac{1}{2} \delta^{2} E V_{R}^{\prime s}
$$

where $V_{R}^{S}$ is the retailer's optimal value function.

Optimizing the right-hand side of the retailer's function, the product price-response strategy of the retailer can be obtained as follows:

$$
p=\frac{a+b w}{2 b}
$$

This paper uses continuous-time dynamic programming theory to obtain the HJB equation. In addition, the optimal wholesale price and carbon emission-reduction effort strategy of the manufacturer should satisfy the following HJB equation:

$$
\begin{aligned}
& \rho V_{M}^{S}=\max _{Z_{M} \geq 0}\left\{\left(w-c-p_{e} e_{M}+p_{e} g_{M}\right)(a-b p) k E-(1-\xi) \frac{\mu_{M}(1-\tau)}{2} Z_{M}^{2}+p_{e} E\right. \\
& \left.+V_{M}^{S}\left(\alpha Z_{M}-\sigma E\right)\right\}+\frac{1}{2} \delta^{2} E V_{M}^{\prime S} .
\end{aligned}
$$

The retailer's product price reflecting strategy is introduced into the above formula, which can be solved as

$$
\begin{aligned}
\rho V_{M}^{S} & =\max _{Z_{M} \geq 0}\left\{\left(w-c-p_{e} e_{M}+p_{e} g_{M}\right)\left(\frac{a-b w}{2}\right) k E-(1-\xi) \frac{\mu_{M}(1-\tau)}{2} Z_{M}^{2}\right. \\
& \left.+p_{e} E+V_{M}^{S}\left(\alpha Z_{M}-\sigma E\right)\right\}+\frac{1}{2} \delta^{2} E V_{M}^{S},
\end{aligned}
$$

where $V_{M}^{S}$ is the optimal value function of the manufacturer.

$$
\begin{aligned}
w^{*} & =\frac{1}{2 b}\left(a+b c+b p_{e} e_{M}-b p_{e} g_{M}\right), \\
Z_{M}^{*} & =\frac{V_{M}^{S}}{(1-\xi)(1-\tau)} \frac{\alpha}{\mu_{M}} .
\end{aligned}
$$
price and optimal carbon emission-reduction effort are as follows: 
Substituting the emission-reduction effort into the retailer's HJB equation, and making the first-order partial derivative equal to zero, we can obtain the following result:

$$
\xi=\frac{2 V_{R}^{S}-V_{M}^{S}}{2 V_{R}^{S}+V_{M}^{S}} .
$$

To obtain the strategies of the manufacturer and retailer, it is necessary to determine their optimal value functions. These are obtained by introducing the strategies of manufacturer and retailer.

$$
\begin{aligned}
& \rho V_{M}^{S}=\max _{Z_{M} \geq 0}\left\{\left[\frac{1}{8 b}\left(a-b c-b p_{e} e_{M}+b p_{e} g_{M}\right)^{2} k-V_{M}^{S^{\prime}} \sigma+p_{e}+\frac{1}{2} \delta^{2} V_{M}^{S^{\prime \prime}}\right] E-\frac{\alpha^{2} V_{M}^{S^{\prime}}\left(2 V_{R}^{S^{\prime}}+V_{M}^{S^{\prime}}\right)}{4 \mu_{M}(1-\tau)}\right\}, \\
& \rho V_{R}^{S}=\max _{p, \xi}\left\{\begin{array}{c}
{\left[\frac{1}{16 b}\left(a-b c-b p_{e} e_{M}+b p_{e} g_{M}\right)^{2} k-V_{R}^{S^{\prime}} \sigma+\frac{1}{2} \delta^{2} V_{R}^{s^{\prime \prime}}\right] E} \\
V_{R}^{S^{\prime}} \alpha^{2}\left(2 V_{R}^{S^{\prime}}+V_{M}^{S^{\prime}}\right) \\
+\frac{\alpha^{2}\left(2 V_{R}^{S^{\prime}}-V_{M}^{S^{\prime}}\right)\left(2 V_{R}^{S^{\prime}}+V_{M}^{S^{\prime}}\right)}{8 \mu_{M}(1-\tau)}-\frac{\mu^{\prime}(1-\tau)}{2}
\end{array}\right\} .
\end{aligned}
$$

Solving the differential equation system separately, the optimal value functions of the manufacturer and retailer are as follows:

$$
\left\{\begin{array}{l}
V_{M}^{S}=f_{1} E^{2}+f_{2} E+f_{3}, \\
V_{R}^{S}=g_{1} E^{2}+g_{2} E+g_{3} .
\end{array}\right.
$$

The first and second derivatives of the optimal value function of the manufacturer and the retailer are given by

$$
\left\{\begin{array}{l}
V_{M}^{S^{\prime}}=2 f_{1} E+f_{2}, \\
V_{R}^{S^{\prime}}=2 g_{1} E+g_{2},
\end{array}\right.
$$

$$
\left\{\begin{array}{l}
V_{M}^{S^{\prime \prime}}=2 f_{1}, \\
V_{R}^{S^{\prime \prime}}=2 g_{1} .
\end{array}\right.
$$

To make the optimal value functions of the manufacturer and the retailer assumed in equation (17) is the solution of equations (15) and (16), substituting equations (17)-(19), respectively, into equations (15) and (16), which can be solved as

$$
\begin{aligned}
& \left\{\begin{array}{l}
\rho f_{1}=\frac{\alpha^{2}\left(2 f_{1} g_{1}+f_{1}^{2}\right)}{\mu_{M}(1-\tau)}-2 \sigma f_{1}, \\
\rho f_{2}=\frac{\left(a-b c-b p_{e} e_{M}+b p_{e} g_{M}\right)^{2} k+8 b p_{e}+8 b \delta^{2} f_{1}-8 b \sigma f_{2}}{8 b}+\frac{\alpha^{2}\left(f_{1} g_{2}+f_{2} g_{1}+f_{1} f_{2}\right)}{\mu_{M}(1-\tau)} \\
\rho f_{3}=\frac{\alpha^{2} f_{2}\left(2 g_{2}+f_{2}\right)}{4 \mu_{M}(1-\tau)}, \\
\rho g_{1}=\frac{\alpha^{2}\left(4 g_{1}+2 f_{1}\right)^{2}}{8 \mu_{M}(1-\tau)}-2 \sigma g_{1}, \\
\rho g_{2}=\frac{\left(a-b c-b p_{e} e_{M}+b p_{e} g_{M}\right)^{2} k+16 b \delta^{2} g_{1}-16 b \sigma g_{2}}{16 b}+\frac{\alpha^{2}\left(2 g_{2}+f_{2}\right)\left(2 g_{1}+f_{1}\right)}{2 \mu_{M}(1-\tau)}, \\
\rho g_{3}=\frac{\alpha^{2}\left(2 g_{2}+f_{2}\right)^{2}}{8 \mu_{M}(1-\tau)} .
\end{array}\right.
\end{aligned}
$$


Equations (20) and (21) are valid for all possible values of carbon emission reduction, which indicates that the coefficients and constant terms on both sides of the equation are equivalent. They can be solved as

$$
\begin{aligned}
& \left\{\begin{array}{l}
f_{1}=-\frac{2(2 \sigma+\rho) \mu_{M}(1-\tau)}{\alpha^{2}} \\
f_{2}=\frac{\left[\left(a-b c-b p_{e} e_{M}+b p_{e} g_{M}\right)^{2} k \alpha^{2}\right.}{4 b \alpha} \\
f_{3}=\frac{\alpha^{2} g_{2} f_{2}}{2 \mu_{M}(1-\tau) \rho}+\frac{\alpha^{2} f_{2}^{2}}{4 \mu_{M}(1-\tau) \rho} \\
g_{1}=\frac{(2 \sigma+\rho) \mu_{M}(1-\tau)}{2 \alpha^{2}} \\
g_{2}=\frac{\left[\left(a-b c-b p_{e} e_{M}+b p_{e} g_{M}\right)^{2} k\right.}{8 \mu_{M}(1-\tau) \rho} . \\
g_{3}=\frac{\alpha^{2}\left(4 g_{2}^{2}+f_{2}^{2}+4 g_{2} f_{2}\right)}{}
\end{array}\right.
\end{aligned}
$$

Firstly, we calculate the coefficient $f_{1}$ according to the given parameters and then calculate the other coefficients. Secondly, we derive the optimal value function according to formula (17). Finally, we use Theorem 1 to obtain the manufacturer's carbon emission-reduction effort and wholesale price, the retailer's retail price, and the carbon emission-reduction cost-sharing ratio.

\section{Characteristics of Evolution in the Emission- Reduction Rate}

Theorem 2. The expectation of random carbon reduction and the expectation limit are, respectively, as follows:

$$
\begin{aligned}
E_{(E)} & =e^{M t}\left(E_{0}+N M^{-1}-N M^{-1} e^{-M t}\right), \\
\lim _{t \longrightarrow \infty} E_{(E)} & =-N M^{-1} .
\end{aligned}
$$

The variance of random carbon reduction and variance limit are, respectively,

$$
\begin{aligned}
D_{(E)}= & e^{2 M t}\left(E_{0}+N M^{-1}-N M^{-1} e^{-M t}\right)^{2}-e^{2 M t}\left(E_{0}^{2}+\left(M E_{0}+N\right)\left(2 N+\delta^{2}\right) M^{-2}-N\left(2 N+\delta^{2}\right)\left(2 M^{2}\right)^{-1}\right) \\
& -e^{M t}\left(M E_{0}+N\right)\left(2 N+\delta^{2}\right) M^{-2}+N\left(2 N+\delta^{2}\right)\left(2 M^{2}\right)^{-1} \\
& \lim _{t \rightarrow \infty} D_{(E)}=N\left(2 N+\delta^{2}\right)\left(2 M^{2}\right)^{-1}-N^{2} M^{-2}
\end{aligned}
$$

where $\quad M=-(3 \sigma+\rho) \quad$ and $\quad N=\alpha^{2}\left(2 g_{2}+f_{2}\right)\left[2 \mu_{M}\right.$ $(1-\tau)]^{-1}$.

Proof. The manufacturer's carbon emission-reduction efforts in Theorem 1 are brought into the process of carbon emission reduction, which can be solved as

$$
\begin{aligned}
\mathrm{d} E(t) & =\left[\alpha Z_{M}(t)-\sigma E(t)\right] \mathrm{d} t+\delta \sqrt{E(t)} \mathrm{d} Z(t), \\
E(0) & =E_{0} .
\end{aligned}
$$

Integrating the two sides by using boundary conditions, it can be solved as

$$
E=E_{0}+\int_{0}^{t}(M E+N) \mathrm{d} t+\int_{0}^{t} \delta \sqrt{E(t)} \mathrm{d} Z(t) .
$$


Taking the expectations on both sides by using the zeromean property of the Wiener process, it can be solved as

$$
E_{(E)}=E_{0}+\int_{0}^{t}\left(M E_{(E)}+N\right) \mathrm{d} t .
$$

Integrating again, it can be solved as

$$
E_{(E)}=e^{M t}\left(E_{0}+N M^{-1}-N M^{-1} e^{-M t}\right) .
$$

When $t \longrightarrow \infty$, we can obtain $M<0$, which can be solved as

$$
\lim _{t \longrightarrow \infty} E_{(E)}=-N M^{-1}
$$

TABle 2: Parameter sensitivity analysis.

\begin{tabular}{lcccc}
\hline & $E\left(E(t)^{*}\right)$ & $Z_{M}^{*}$ & $w^{*}$ & $p^{*}$ \\
\hline$k$ & $\uparrow$ & $\uparrow$ & $\longrightarrow$ & $\longrightarrow$ \\
$\mu_{M}$ & $\downarrow$ & $\downarrow$ & $\longrightarrow$ & $\longrightarrow$ \\
$\alpha$ & $\uparrow$ & $\uparrow$ & $\longrightarrow$ & $\longrightarrow$ \\
$p_{e}$ & $\uparrow$ & $\uparrow$ & $\downarrow$ & $\downarrow$ \\
$\tau$ & $\uparrow$ & $\uparrow$ & $\longrightarrow$ & $\longrightarrow$ \\
\hline
\end{tabular}

Based on the ITO theorem, we determine the change process of the square of carbon reduction, which can be solved as

$$
\begin{aligned}
\mathrm{d} E^{2} & =\left[2 M E^{2}+(2 N+\delta)^{2} E\right] \mathrm{d} t+2 \delta E \sqrt{E(t)} \mathrm{d} Z(t), \\
E^{2}(0) & =E_{0}^{2} .
\end{aligned}
$$

Integrating the two sides by using boundary conditions, we obtain

$$
E^{2}=E_{0}^{2}+\int_{0}^{t}\left(2 M E^{2}+\left(2 N+\delta^{2}\right) E\right) \mathrm{d} t+\int_{0}^{t} 2 E \delta \sqrt{E(t)} \mathrm{d} Z(t) .
$$

Taking the expectations on both sides by using the zeromean property of the Wiener process, we can obtain

$$
E_{\left(E^{2}\right)}=E_{0}^{2}+\int_{0}^{t}\left(2 M E_{\left(E^{2}\right)}+\left(2 N+\delta^{2}\right) E_{(E)}\right) \mathrm{d} t .
$$

$$
E_{\left(E^{2}\right)}=e^{2 M t}\left(E_{0}^{2}+\frac{\left(M E_{0}+N\right)\left(2 N+\delta^{2}\right)}{M^{2}}-\frac{N\left(2 N+\delta^{2}\right)}{2 M^{2}}\right)-e^{M t} \frac{\left(M E_{0}+N\right)\left(2 N+\delta^{2}\right)}{M^{2}}+\frac{N\left(2 N+\delta^{2}\right)}{2 M^{2}} .
$$

We then determine the variance in carbon reduction according to the following equation:

$$
D_{(E)}=E_{\left(E^{2}\right)}-\left[E_{(E)}\right]^{2} .
$$

Considering $\quad M<0$, we get $\quad \lim _{t \rightarrow \infty}$ $E_{\left(E^{2}\right)}=\left(\left(N\left(2 N+\delta^{2}\right)\right) /\left(2 M^{2}\right)\right)$. Thus, the variance limit of emission reduction is $\lim _{t \rightarrow \infty} D_{(E)}=\lim _{t \rightarrow \infty} E_{\left(E^{2}\right)}-$ $\lim _{t \rightarrow \infty}\left[E_{(E)}\right]^{2}=\left(\left(N\left(2 N+\delta^{2}\right)\right) /\left(2 M^{2}\right)\right)-\left(N^{2} / M^{2}\right)$. It is assumed that the process of carbon emission reduction does not produce random interference $(\delta=0)$; that is, $\lim _{t \rightarrow \infty} E_{\left(E^{2}\right)}=\left(N^{2} / M^{2}\right) ;$ thus, $\quad D_{(E)}=E_{\left(E^{2}\right)^{-}}\left[E_{(E)}\right]^{2}$ $=0$.

\section{Parameter Sensitivity Analysis}

Assume that the consumer low-carbon preference coefficient is $k$, the emission-reduction effort influence coefficient of manufacturer is $\alpha$, the emission-reduction cost coefficient is $\mu_{M}$, the carbon trading price is $p_{e}$, and the cost subsidy rate is $\tau$. We then calculate the impact of the above parameters on the optimal emission-reduction effort, wholesale price, retail 
price, and emission reduction. The results are shown in Table 2 .

Inference 1. Under the coordinated decision-making of cost subsidy, the increase in the consumer low-carbon preference coefficient will lead to increased carbon emissions. The manufacturers will increase their emission-reduction efforts, and the wholesale price of the manufacturer and the retail price of the retailer will remain invariant.

Proof

$$
\begin{aligned}
\frac{\partial p^{*}}{\partial k} & =0, \\
\frac{\partial w^{*}}{\partial k} & =0, \\
\frac{\partial Z_{M}^{*}}{\partial k} & =-\frac{(2 \sigma+\rho)}{\alpha} \frac{\mathrm{d} E_{(E)}}{\mathrm{d} k}+\frac{\left(a-b c-b p_{e} e_{M}+b p_{e} g_{M}\right)^{2} \alpha(6 \sigma+5 \rho)}{16 b \mu_{M}(1-L)\left[(3 \sigma+2 \rho)(8 \sigma+5 \rho)-2(2 \sigma+\rho)^{2}\right]}>0 . \\
\frac{\partial M}{\partial k} & =0 .
\end{aligned}
$$

Inference 2. Under the coordinated decision-making of cost subsidy, with increases in the manufacturer's emission-reduction cost coefficient, the system's carbon emission reductions will decrease, the manufacturer will reduce emission-reduction efforts, and the manufacturer's wholesale price and retailer's retail price will remain invariant.

Proof

$$
\begin{aligned}
& \frac{\partial p^{*}}{\partial \mu_{M}}=0, \\
& \frac{\partial w^{*}}{\partial \mu_{M}}=0, \\
& \frac{\partial Z_{M}^{*}}{\partial \mu_{M}}=-\frac{(2 \sigma+\rho)}{\alpha} \frac{\mathrm{d} E_{(E)}}{\mathrm{d} \mu_{M}}-\frac{\left(a-b c-b p_{e} e_{M}+b p_{e} g_{M}\right)^{2} k \alpha(6 \sigma+5 \rho)+16 b \alpha p_{e}(\sigma+\rho)}{16 b \mu_{M}^{2}(1-L)\left[(3 \sigma+2 \rho)(8 \sigma+5 \rho)-2(2 \sigma+\rho)^{2}\right]}<0, \\
& \frac{\partial M}{\partial \mu_{M}}=0, \quad \\
& \frac{\partial N}{\partial \mu_{M}}=-\frac{\left(a-b c-b p_{e} e_{M}+b p_{e} g_{M}\right)^{2} k \alpha^{2}(6 \sigma+5 \rho)+16 b \alpha^{2} p_{e}(\sigma+\rho)}{16 b \mu_{M}^{2}(1-L)\left[(3 \sigma+2 \rho)(8 \sigma+5 \rho)-2(2 \sigma+\rho)^{2}\right]}<0 .
\end{aligned}
$$

Inference 3. Under the coordinated decision-making of cost subsidy, increases in the emission-reduction cost coefficient will lead to increases in carbon emission reductions, the manufacturers will increase carbon emission-reduction efforts, and the manufacturer's wholesale price and retailer's retail price will remain invariant. 
Proof

$$
\begin{aligned}
\frac{\partial p^{*}}{\partial \alpha} & =0, \\
\frac{\partial w^{*}}{\partial \alpha} & =0, \\
\frac{\partial Z_{M}^{*}}{\partial \alpha} & =\frac{(2 \sigma+\rho)\left(E-\alpha\left(\mathrm{d} E_{(E)} / \mathrm{d} \alpha\right)\right)}{\alpha^{2}}+\frac{8 b \delta^{2} \rho(2 \sigma+\rho)}{16 b \alpha^{2}\left[(3 \sigma+2 \rho)(8 \sigma+5 \rho)-2(2 \sigma+\rho)^{2}\right]}>0, \\
\frac{\partial M}{\partial \alpha} & =0, \\
\frac{\partial N}{\partial \alpha} & =\frac{\left(a-b c-b p_{e} e_{M}+b p_{e} g_{M}\right)^{2} k \alpha(6 \sigma+5 \rho)+16 b \alpha p_{e}(\sigma+\rho)}{8 b \mu_{M}(1-L)\left[(3 \sigma+2 \rho)(8 \sigma+5 \rho)-2(2 \sigma+\rho)^{2}\right]}>0 .
\end{aligned}
$$

Inference 4. Under the coordinated decision-making of cost subsidy, increases in the carbon trading price will lead to increases in carbon emission reduction, the manufacturers will reduce their emission-reduction efforts, and at the same time, the manufacturers will reduce their wholesale price and retailers will reduce their retail price.

Proof

$$
\begin{aligned}
\frac{\partial p^{*}}{\partial p_{e}} & =\frac{1}{4}\left(e_{M}-g_{M}\right)<0, \\
\frac{\partial w^{*}}{\partial p_{e}} & =\frac{1}{2}\left(e_{M}-g_{M}\right)<0, \\
\frac{\partial Z_{M}^{*}}{\partial p_{e}} & =-\frac{(2 \sigma+\rho)}{\alpha} \frac{\mathrm{d} E_{(E)}}{\mathrm{d} p_{e}}+\frac{8 \alpha(\sigma+\rho)+\left(a-b c-b p_{e} e_{M}+b p_{e} g_{M}\right) k \alpha\left(g_{M}-e_{M}\right)(6 \sigma+5 \rho)}{8 \mu_{M}(1-L)\left[(3 \sigma+2 \rho)(8 \sigma+5 \rho)-2(2 \sigma+\rho)^{2}\right]}>0, \\
\frac{\partial M}{\partial p_{e}} & =0 \\
\frac{\partial N}{\partial p_{e}} & =\frac{8 \alpha^{2}(\sigma+\rho)+\left(a-b c-b p_{e} e_{M}+b p_{e} g_{M}\right) k \alpha^{2}\left(g_{M}-e_{M}\right)(6 \sigma+5 \rho)}{8 \mu_{M}(1-L)\left[(3 \sigma+2 \rho)(8 \sigma+5 \rho)-2(2 \sigma+\rho)^{2}\right]}>0 .
\end{aligned}
$$

Inference 5. Under the coordinated decision-making of cost subsidy, increases in the cost subsidy rate will lead to increases in carbon emission reduction, the manufacturers will increase their emission-reduction efforts, and the wholesale price of manufacturers and the retail price of retailers will remain invariant. 


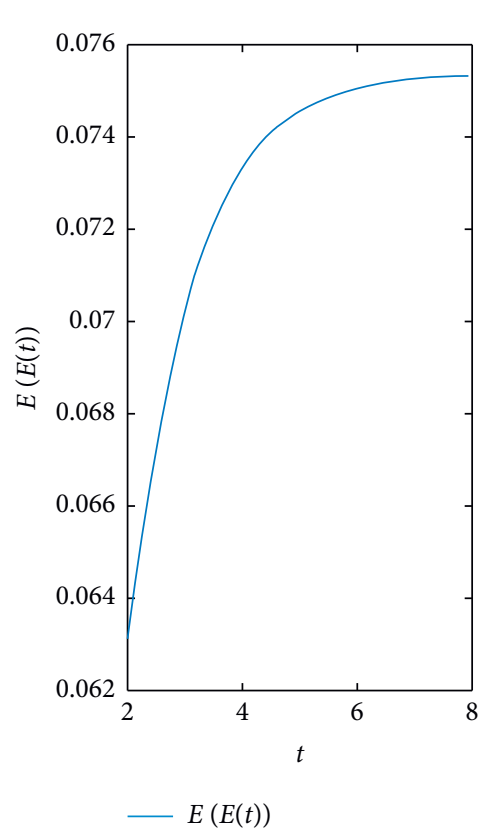

(a)

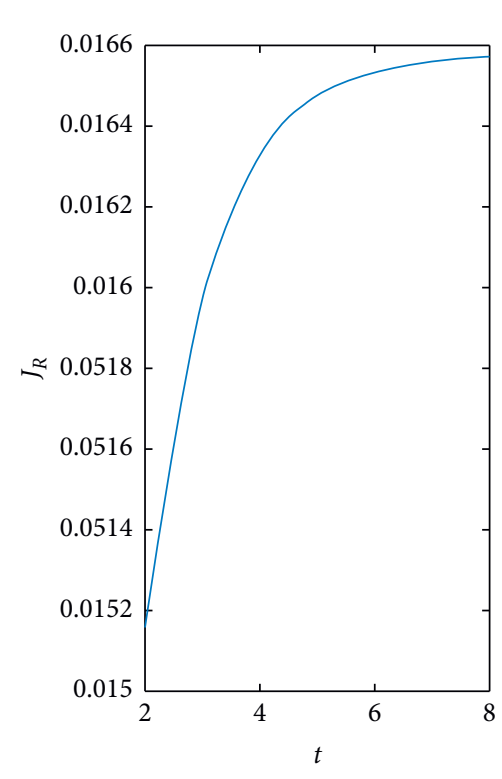

$-J_{R}$

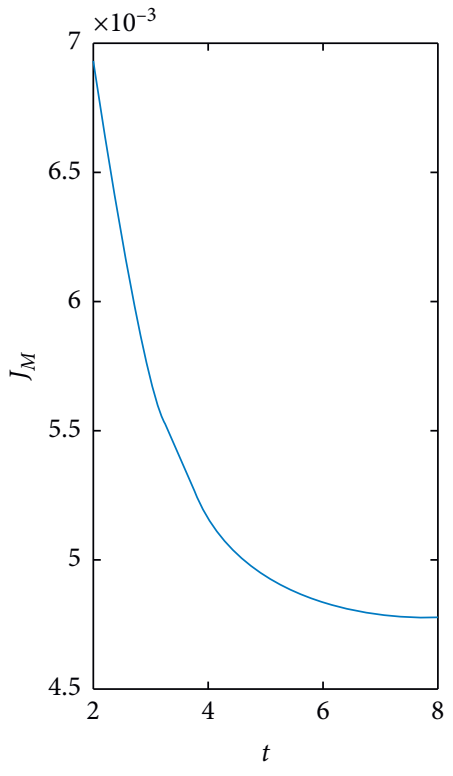

$-J_{M}$

(b)

Figure 2: State variable trajectories under a cost-sharing and coordinated decision-making scenario.

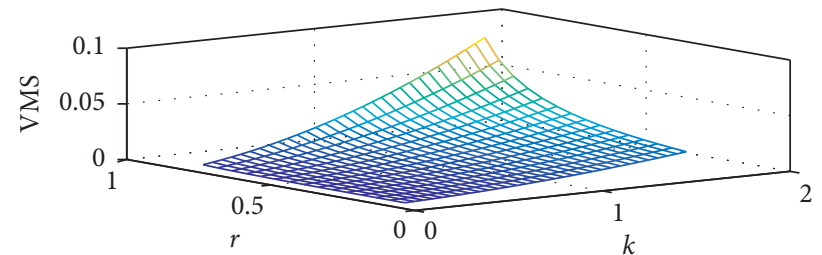

(a)

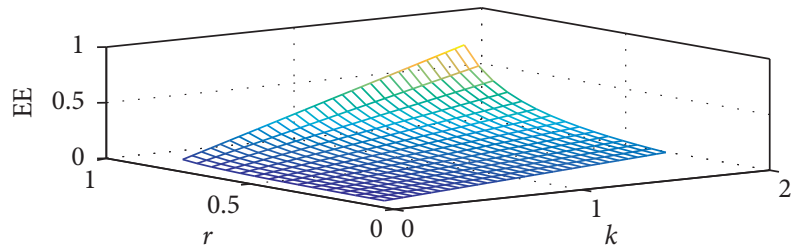

(c)

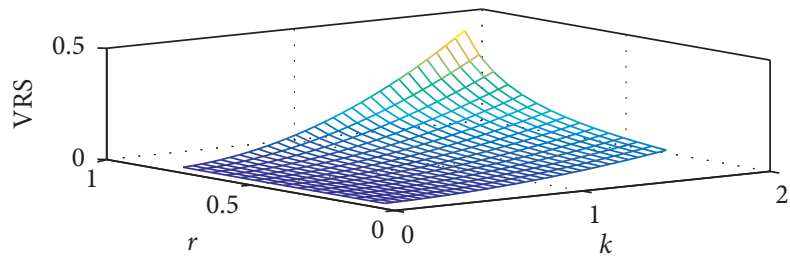

(b)

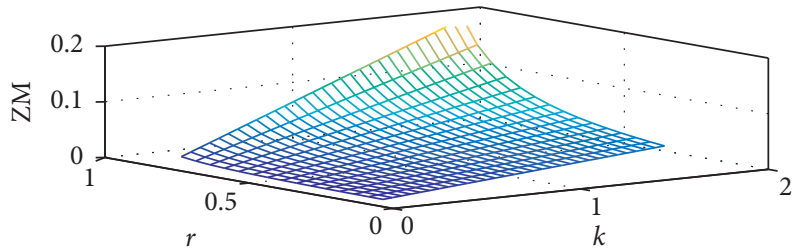

(d)

Figure 3: Sensitivity analysis of consumers' carbon sensitivity coefficient and cost subsidy rate. 


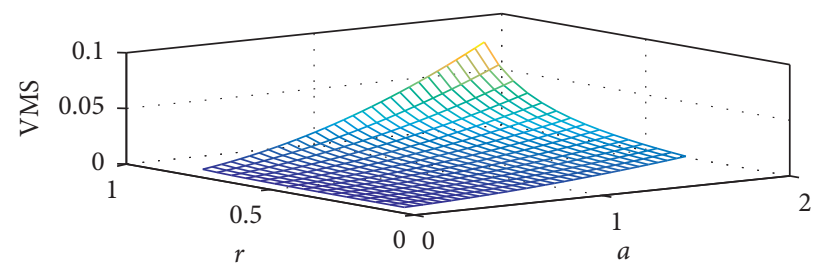

(a)

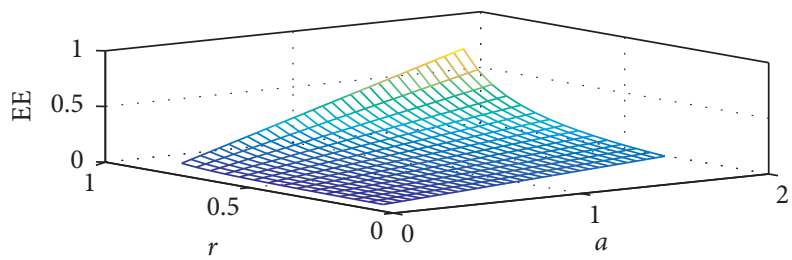

(c)

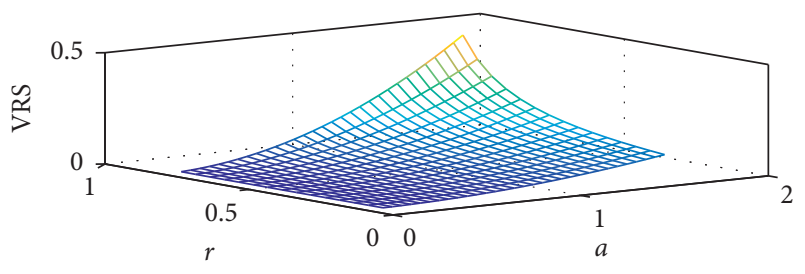

(b)

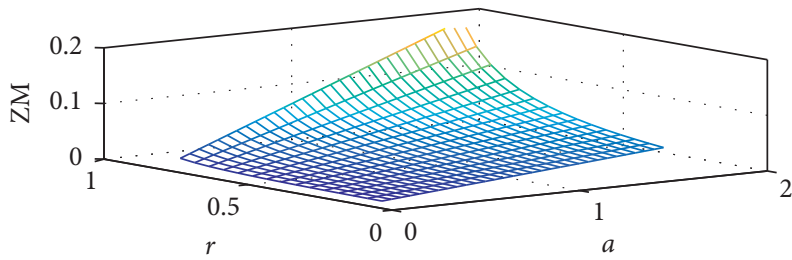

(d)

Figure 4: Sensitivity analysis of efforts influence coefficient and cost subsidy rate.

Proof

$$
\begin{aligned}
\frac{\partial p^{*}}{\partial \tau} & =0, \\
\frac{\partial w^{*}}{\partial \tau} & =0, \\
\frac{\partial M}{\partial \tau} & =0, \\
\frac{\partial N}{\partial \tau} & =\frac{8 b \delta^{2} \rho(2 \sigma+\rho)}{16 b\left[(3 \sigma+2 \rho)(8 \sigma+5 \rho)-2(2 \sigma+\rho)^{2}\right]}>0, \\
\frac{\partial Z_{M}^{*}}{\partial \tau} & =-\frac{(2 \sigma+\rho)}{\alpha} \frac{\mathrm{d} E_{(E)}}{\mathrm{d} \tau}+\frac{8 b \delta^{2} \rho(2 \sigma+\rho)}{16 b \alpha\left[(3 \sigma+2 \rho)(8 \sigma+5 \rho)-2(2 \sigma+\rho)^{2}\right]}>0 .
\end{aligned}
$$

\section{Numerical Example}

7.1. Evolution Path Analysis. This paper intuitively analyses the supply chain's optimal strategic trajectory under costsharing and coordinated decision-making through parameter assignment. The parameters of this paper are set as follows: $\rho=0.3, \sigma=0.2, a=4.5, b=1, c=3, \alpha=0.8$, $p_{\mathrm{e}}=0.02, \quad k=0.6, \quad \mu_{\mathrm{M}}=1, \quad e_{\mathrm{M}}=0.5, \quad g_{\mathrm{M}}=2, \quad E \quad(0)=0$, $\tau=0.15$, and $\delta=0.01$. The trajectory of the supply chain's profit and emission reductions under cost-sharing and coordinated decision-making can be obtained, as shown in Figure 2.

In Figure 2, the carbon emission reductions and retailer profit show nonlinear upward trends with time, and the rate of increase becomes slower and slower and finally becomes stable. The change of manufacturer's profit is opposite to that of the retailer.

\subsection{Sensitivity Analysis}

7.2.1. Sensitivity Analysis of $\tau$ and $k$. Assuming that other parameters remain unchanged, the simulation of the cost subsidy rate and consumer low-carbon sensitivity coefficient is as shown in Figure 3.

As shown in Figure 3, the manufacturer profit, retailer profit, product carbon emissions, and the emission-reduction effort of the manufacturer increase with increases in the cost subsidy rate and consumer low-carbon sensitivity coefficient. However, the impacts of the cost 


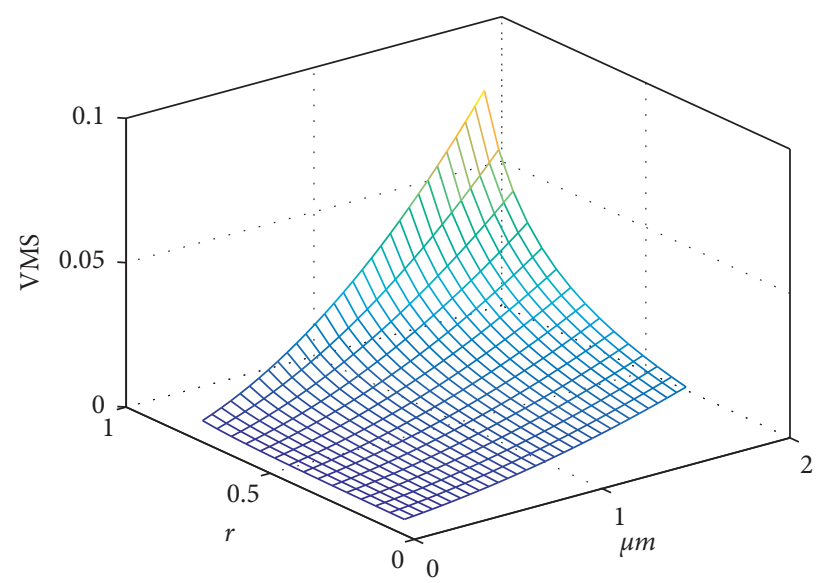

(a)

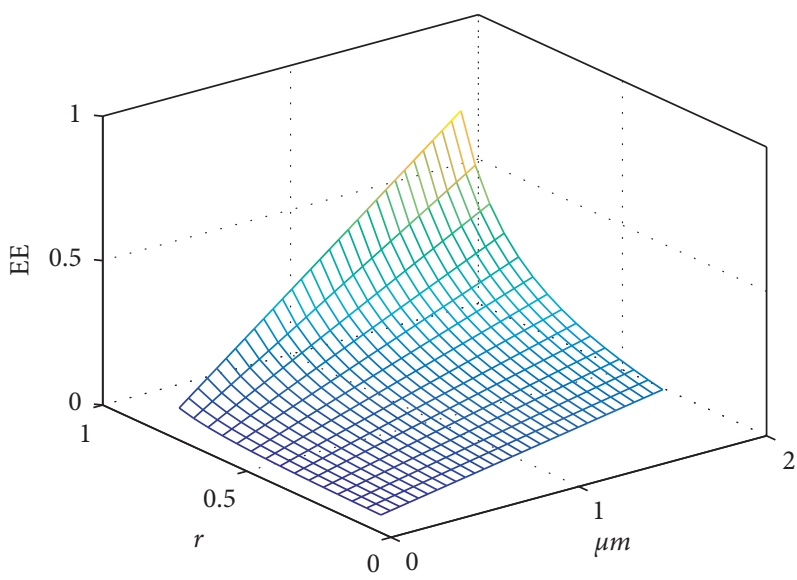

(c)

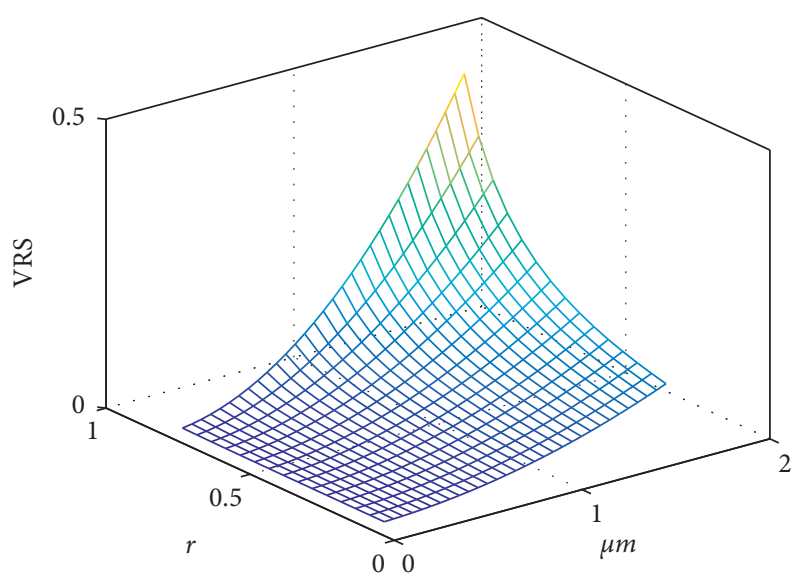

(b)

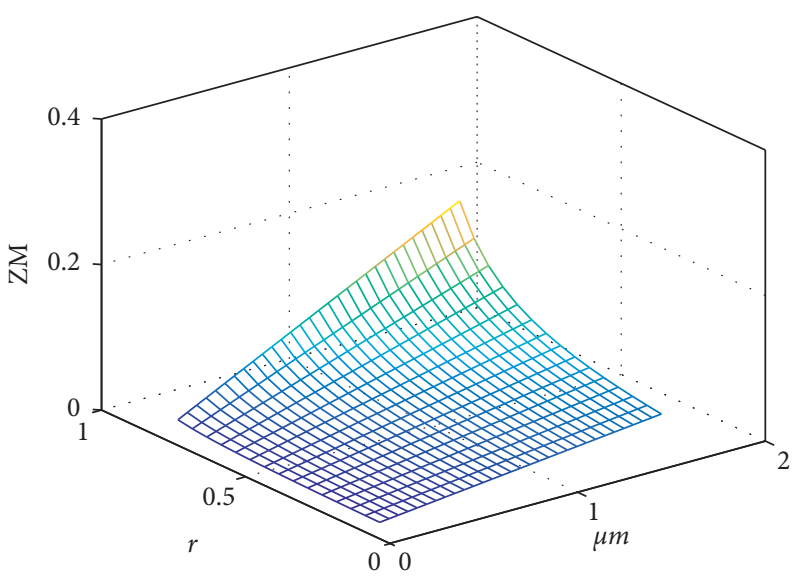

(d)

FIGURE 5: Sensitivity analysis of emission-reduction efforts, cost coefficient, and cost subsidy rate.

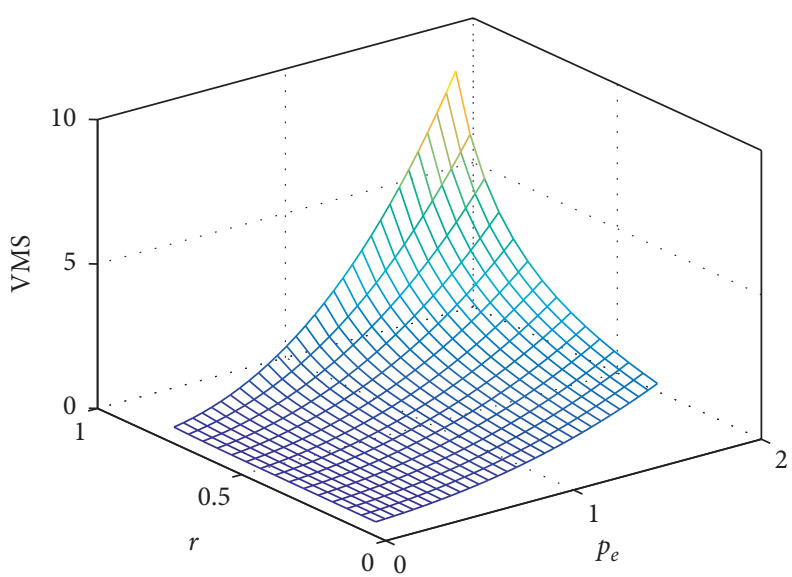

(a)

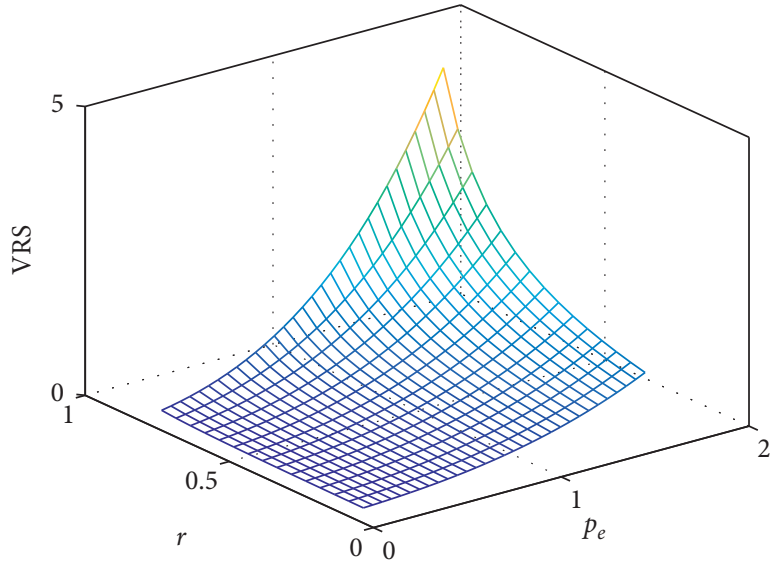

(b)

FIgUre 6: Continued. 


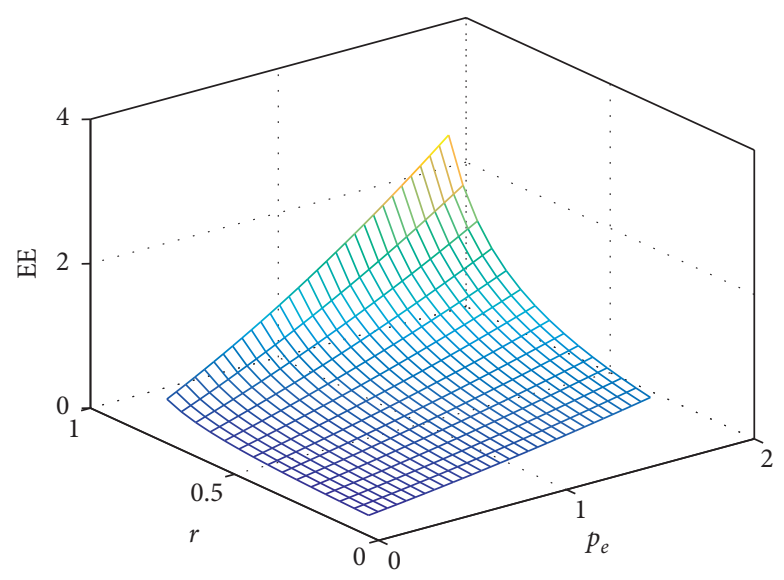

(c)

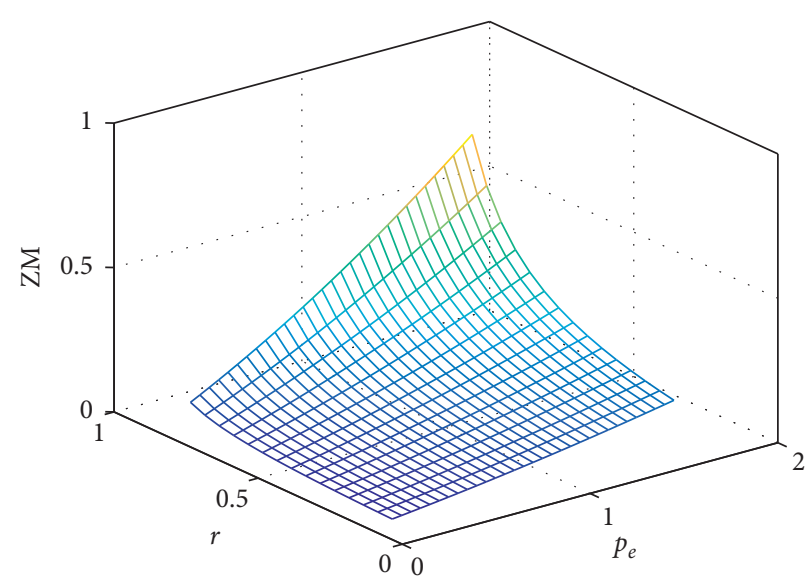

(d)

FIgURE 6: Sensitivity analysis of carbon trading price and cost subsidy rate.

subsidy rate and consumer low-carbon sensitivity coefficient on the parameters are different. When the government subsidy rate is fixed, the consumer low-carbon sensitivity coefficient positively affects product carbon emissions, the emission-reduction effort of the manufacturer, and the profits of upstream and downstream enterprises in the supply chain. At the same time, the cost subsidy rate enhances the impact of the low-carbon sensitivity coefficient on the parameters, indicating that government subsidies can incentivize enterprises to invest in carbon emission reduction.

7.2.2. Sensitivity Analysis of $\tau$ and $\alpha$. When other parameters remain unchanged, the simulation results of the cost subsidy rate and impact coefficient of manufacturers' emission-reduction efforts are as shown in Figure 4.

As shown in Figure 4, the manufacturer profit, retailer profit, product carbon emissions, and manufacturer emission-reduction effort increase with increases in the cost subsidy rate and impact coefficient of manufacturers' emission-reduction efforts. However, the influences of the cost subsidy rate and manufacturer's emission-reduction effort influence coefficient on parameters are different. When the government subsidy rate is fixed, manufacturer's emission-reduction effort influence coefficient positively affects the product carbon emissions, manufacturer emission-reduction effort, and the profits of the upstream and downstream enterprises in the supply chain. Meanwhile, the introduction of government subsidies enhances the influence of the manufacturers' emission-reduction impact coefficient on the parameters, indicating that government subsidies can incentivize enterprises to invest in carbon emission reductions.

7.2.3. Sensitivity Analysis of $\tau$ and $\mu_{m}$. With other parameters unchanged, the simulation results of the cost subsidy rate and cost coefficient of carbon emission reduction are as shown in Figure 5.
As shown in Figure 5, the manufacturer profit, the retailer profit, product carbon emissions, and the manufacturer emission-reduction effort increase with increases in the cost subsidy rate and cost coefficient of carbon emission reduction, but the effects of the latter two are different. When the government subsidy rate is fixed, the cost coefficient of carbon emission reduction has a negative influence on product carbon emissions, manufacturer emission-reduction efforts, and supply chain members' profits. These parameters all decrease with increases in the cost coefficient of carbon emission reduction, but the increase in government subsidy rate leads to an increase in carbon emissions, manufacturer emission-reduction effort, and the profits of the upstream and downstream enterprises in the supply chain. Moreover, the influence of the government subsidy rate on the parameters is greater than that of the emission-reduction effort cost coefficient, so these parameters show an upward trend. Thus, government subsidies can incentivize enterprises to invest in carbon emission reductions.

7.2.4. Sensitivity Analysis of $\tau$ and $p_{e}$. With other parameters unchanged, the simulation results of cost subsidy rate and carbon trading price are as shown in Figure 6.

As shown in Figure 6, manufacturer profit, retailer profit, product carbon emissions, and manufacturer emission-reduction effort increase with increases in the cost subsidy rate and carbon trading price, but the influences of the latter two are different. When the government subsidy rate is fixed, the carbon trading price positively affects the product carbon emissions, manufacturer emission-reduction effort, and the profits of the upstream and downstream enterprises in the supply chain. At the same time, the introduction of a government subsidy enhances the influence coefficient of carbon trading price on the parameters, which shows that government subsidies can incentivize enterprises to invest in carbon emission reduction. 


\section{Conclusions}

Under the background of economic globalization, supply chain enterprises can only improve their competitiveness and achieve the goal of sustainable development by formulating specific strategies and measures based on the perspective of sustainable development. In order to achieve sustainable development, supply chain enterprises need to follow the steps of the world closely and abide by the carbon rules of the international community and international organizations. Supply chain enterprises should give consideration to both economic and ecological benefits and maximize benefits with the minimum cost and carbon emissions. Therefore, this paper comprehensively considered the influences of an efficiency-based carbon quota system and an incentive-based cost subsidy system on supply chain emission-reduction investment decisions. From a dynamic perspective, this paper considered consumer lowcarbon preferences and the randomness of the emissionreduction process. We used a stochastic differential game model to determine the equilibrium strategies of the government, supply chain, and consumers, the evolution path of carbon emission reduction, and manufacturer and retailer profits.

To characterize the impact of carbon trading price, cost subsidy rate, consumer low-carbon preferences, and various uncontrollable factors on supply chain emission-reduction technology decision process, this paper used the zero-mean property of the Wiener process and the Ito theorem to describe the carbon emission-reduction decision-making process under stochastic circumstances. According to the profit structure of the manufacturer and retailer, this paper analysed the profit objective function of the manufacturer and retailer. Based on the supply chain emission-reduction technology decision process and the profit objective function of the manufacturer and retailer, this paper established a Stackelberg stochastic differential game model of a dynamic supply chain system. Using a stochastic differential game model and dynamic optimization method, we obtained the manufacturer's equilibrium wholesale price, manufacturer's equilibrium emission-reduction effort, retailer's equilibrium product price, retailer's equilibrium emission reductions, cost-sharing rate, and the optimal function of upstream and downstream enterprises' profits in the supply chain.

This paper analysed the sensitivity of each parameter to the carbon emission-reduction process in supply chain. The results show that the consumer low-carbon sensitivity coefficient, manufacturer carbon emission-reduction effort coefficient, carbon trading price, and cost subsidy rate have positive effects on carbon system emissions and supply chain profits. The cost coefficient of emission reduction has negative impacts on carbon system emissions and supply chain profits. To grasp the statistical characteristics of stochastic carbon emission reduction in the system, this paper also analysed the statistical properties of expectation and variance. Finally, this paper simulated and assigned the parameters, intuitively analysed the optimal strategy trajectory of the supply chain under costsharing coordination decisions, and verified the influence of different parameter changes on carbon emission-reduction behaviour.

This paper discussed the dynamic investment decisions of carbon emission-reduction technology in an ideal secondary supply chain with one supplier and one retailer under a cost-sharing coordination decision scenario. However, the simple secondary supply chain is too idealistic and does not meet actual development needs. Future research will focus on investment decision-making related to carbon emission reductions in a multilevel supply chain.

\section{Data Availability}

The data used to support the findings of this study are included within the article.

\section{Conflicts of Interest}

The authors declare no conflicts of interest.

\section{Authors' Contributions}

Q. H and S. Y conceptualized the study, validated the study, and performed data curation. Q. H was responsible for methodology, software, project administration, and funding acquisition and supervised the study. S. Y performed formal analysis, investigated the data, prepared the original draft, reviewed and edited the manuscript, and visualized the study and was responsible for resources.

\section{Acknowledgments}

This research was funded by Liaoning Province Social Science Foundation, grant no. 2019-ZD-0214.

\section{References}

[1] M. Świąder, S. Szewrański, and J. K. Kazak, "Environmental carrying capacity assessment-the policy instrument and tool for sustainable spatial management," Frontiers in Environmental Science, 2020.

[2] P. Pascal, V. Patrick, and D. W. Renwick, "Leveraging green human resource practices to achieve environmental sustainability," Journal of Cleaner Production, p. 260, 2020.

[3] M. F. Bashir, B. Ma, and M. Shahbaz, "The nexus between environmental tax and carbon emissions with the roles of environmental technology and financial development," PLoS One, vol. 15, no. 11, 2020.

[4] D. Nong, C. Wang, and Q. A. Abul, "A critical review of energy resources, policies and scientific studies towards a cleaner and more sustainable economy in Vietnam," Renewable and Sustainable Energy Reviews, p. 134, 2020.

[5] S. Jackson, L. Palmer, and M. Fergus, "Cultures of carbon and the logic of care: the possibilities for carbon enrichment and its cultural signature," Annals of the American Association of Geographers, vol. 107, no. 4, 2017.

[6] K. Harrahill and O. Douglas, "Framework development for 'just transition' in coal producing jurisdictions," Energy Policy, p. 134, 2019.

[7] J. Amundson, W. Faulkner, and S. Sukumara, "A bayesian network based approach for risk modeling to aid in 
sustainable development biomass supply chains," Computer Aided Chemical Engineering, vol. 30, 2012.

[8] S. Benjaafar, Y. Li, and M. Daskin, "Carbon footprint and the management of supply chains: insights from simple models," IEEE Transactions on Automation Science and Engineering, vol. 10, no. 1, pp. 99-116, 2013.

[9] J. Y. Song, R. W. Li, and L. Guo, "Research on the construction of product carbon chain in supply chain and calculation of carbon footprint based on discriminant factors," The International Journal of Advanced Manufacturing Technology, vol. 111, no. 1-2, pp. 589-596, 2020.

[10] S. Elhedhli and R. Merrick, "Green supply chain network design to reduce carbon emissions," Transportation Research Part D: Transport and Environment, vol. 17, no. 5, pp. 370379, 2012.

[11] Z. Dai and K. Hu, "Multi-objective low carbon loop supply chain network optimization model and algorithm," Application Research of Computers, vol. 31, no. 6, pp. 1648-1653, 2014.

[12] L. L. Chen, P. Guo, and E. D. Han, "Optimal decision model for supply chain under carbon tax based on fuzzy theory," Computer Integrated Manufacturing Systems, vol. 23, no. 4, pp. 860-866, 2017.

[13] G. Lou, H. Xia, J. Zhang, and T. Fan, "Investment strategy of emission-reduction technology in a supply chain," Sustainability, vol. 7, no. 8, pp. 10684-10708, 2015.

[14] Q. F. Fu, L. Y. Yi, and S. H. Ma, "Evolutionary game of carbon emission reduction input of supply chain enterprises under penalty mechanism," Journal of Management Science, vol. 19, no. 4, pp. 56-70, 2016.

[15] B. Y. Liu, Z. S. Hua, and Q. H. Zhang, "Optimal operational decision making of manufacturers and authorized remanufacturers with patent licensing under carbon cap-and-trade regulations," Complexity, vol. 2020, Article ID 1864641, 22 pages, 2020.

[16] D. Z. Zhao, B. Y. Yuan, L. J. Xia et al., "Dynamic game study in supply chain with manufacturers' competition under the constraint of productions' emission," Industrial Engineering and Management, vol. 19, no. 1, pp. 65-71, 2014.

[17] L. Yang, C. Zheng, and M. Xu, "Comparisons of low carbon policies in supply chain coordination," Journal of Systems Science and Systems Engineering, vol. 23, no. 3, pp. 342-361, 2014.

[18] J. Xu, Y. Chen, and Q. Bai, “A two-echelon sustainable supply chain coordination under cap-and-trade regulation," Journal of Cleaner Production, vol. 135, pp. 42-56, 2016.

[19] S. H. Yang and P. Wang, "Two level low carbon supply chain game and optimization based on carbon quota policy," Control and Decision, vol. 31, no. 5, pp. 924-928, 2016.

[20] C. M. Xu, D. Z. Zhao, and Q. G. Du, "Decision and coordination models for supply chain with carbon emissions reduction level and price dependent demand," Control and Decision, vol. 31, no. 3, pp. 486-492, 2016.

[21] H. J. Zhang, J. Y. Zhang, and M. Y. Lai, "Game analysis of government behaviour and supply chain cooperative R\&D under low carbon background," China Management Science, vol. 23, no. 10, pp. 57-66, 2015.

[22] K. Kang, Y. J. Zhao, and J. Zhang, "Evolutionary game theoretic analysis on low-carbon strategy for supply chain enterprises," Journal of Cleaner Production, p. 230, 2019.

[23] L. C. Sun, X. X. Cao, and M. Alharthi, "Carbon emission transfer strategies in supply chain with lag time of emission reduction technologies and low-carbon preference of consumers," Journal of Cleaner Production, p. 264, 2020.
[24] D. P. Wang, T. T. Wang, and B. Q. Zhang, "Differential game of supply chain cooperative emission reduction under government subsidies," Operations Research and Management, vol. 28, no. 5, pp. 46-55, 2019.

[25] H. J. Peng, T. Pang, and J. Cong, "Coordination contracts for a supply chain with yield uncertainty and low-carbon preference," Journal of Cleaner Production, 2018.

[26] Y. D. Li, L. J. Xia, F. Z. Wang et al., "Comparative study on emission reduction strategies of low carbon supply chain considering channel power structure," Management Review, vol. 31, no. 11, pp. 240-254, 2019.

[27] Q. P. Wang, "Study on joint emission reduction and competition dynamic strategy considering the effect of reference emission reduction effort level [J/OL]," Chinese Management Science, vol. 1-11, 2020.

[28] Q. Han, Y. Y. Wang, and L. Shen, "Decision and coordination of low-carbon E-commerce supply chain with government carbon subsidies and fairness concerns," Complexity, vol. 2020, Article ID 1974942, 19 pages, 2020.

[29] D. P. Wang, T. T. Wang, and B. Q. Zhang, "Supply chain cooperative emission reduction and government subsidy strategy based on differential game," . Control and Decision Making, vol. 34, no. 8, pp. 1733-1744, 2019.

[30] Z. R. Wang, A. E. Brownlee, and Q. H. Wu, "Production and joint emission reduction decisions based on two-way costsharing contract under cap-and-trade regulation," Computers \& Industrial Engineering, p. 146, 2020.

[31] J. Wang, "Comparative analysis of supply chain revenue before and after emission reduction based on carbon quota," Journal of Xiangnan University, vol. 39, no. 2, pp. 58-65, 2018.

[32] L. H. Zhang, X. B. Song, G. W. Zhang et al., "Research on coordination of carbon emission reduction technology investment in supply chain based on carbon tax," Computer Integrated Manufacturing System, vol. 23, no. 4, pp. 883-891, 2017.

[33] L. Liu and F. T. Li, "Differential game modelling of joint carbon reduction strategy and contract coordination based on low-carbon reference of consumers," Journal of Cleaner Production, 2020.

[34] Q. H. Zhu, X. Q. Xia, and Y. L. Wang, "Study of the competition between low carbon products and ordinary products manufacturer based on government subsidy," Journal of Systems Engineering, vol. 29, no. 5, pp. 640-651, 2014.

[35] Y. D. Li, D. Z. Zhao, and L. J. Xia, "Governmental subsidy policy for enterprises' cooperative behaviour in emission reduction in low-carbon supply chain," Operations Research and Management Science, vol. 23, no. 4, pp. 1-11, 2014.

[36] J. H. Zhao and J. Lin, "Pricing models of closed-loop supply chain under different subsidy policies," Journal of Industrial Engineering and Engineering Management, vol. 31, no. 1, pp. 85-92, 2017.

[37] S. D. Wei, "Research on differential game of supply chain emission reduction under carbon trading policy," Journal of Management, vol. 15, no. 5, pp. 782-790, 2018.

[38] T. T. Wang, D. P. Wang, and C. Zhao, "Dynamic coordination strategy of supply chain joint emission reduction with the participation of big data service providers[J/OL]," Control and Decision, pp. 1-10, 2020.

[39] J. Y. Mohamad, G. H. Christoph, and M. A. Ahmed, "Supply chain coordination with emissions reduction incentives," International Journal of Production Research, vol. 51, no. 1, pp. 69-82, 2013.

[40] J. Ren, P. He, and B. G. Gong, "Research on government enterprise game and government subsidy strategy in low 
carbon economy," Operations Research and Management, vol. 25, no. 6, pp. 258-265, 2016.

[41] M. Y. Wang, Y. Liu, W. Q. Shi et al., "Research on the strategy and emission reduction benefits of low carbon technology in different places under the carbon trading policy," System Engineering Theory and Practice, vol. 39, no. 6, pp. 1419-1434, 2019.

[42] X. Huang and Z. J. Yuan, "Analysis of carbon tax reduction strategy based on differential game theory," Journal of Hefei University of Technology (NATURAL SCIENCE EDITION), vol. 42, no. 2, pp. 278-283, 2019.

[43] Y. X. Yang, B. Y. Zhang, and L. J. Meng, "Differential game analysis of supply chain network member enterprises under the constraint of carbon emission trading," System Science and Mathematics, vol. 38, no. 10, pp. 1172-1185, 2018.

[44] P. D. Giovanni, "Environmental collaboration in a closed loop supply chain with a reverse revenue sharing contract," Annals of Operations Research, vol. 220, no. 1, pp. 135-157, 2014.

[45] M. W. Liu, M. Y. Wan, and H. Fu, "Low carbon technology selection for supply chain under cap and trade mechanism with low carbon preference," Chinese Journal of Management Science, vol. 26, no. 1, pp. 152-162, 2018.

[46] D. Z. Zhao, B. Y. Yuan, and C. Q. Xu, "Dynamic coordination strategy of vertical cooperative on carbon emission reduction in supply chain under low-carbon era," Journal of Industrial Engineering and Management, vol. 30, no. 1, pp. 147-154, 2016.

[47] T. Ye, Z. M. Guan, J. Tao et al., "Dynamic optimization and coordination about joint emission reduction in a supply chain considering consumer preference to low carbon and reference low-carbon level effect," Chinese Journal of Management Science, vol. 25, no. 10, pp. 52-61, 2017.

[48] D. M. You, G. J. Zhu, and L. Q. Yue, "Differential game analysis of ecological R\&D and promotion in the low-carbon supply chain with mark- up pricing," Soft Science, vol. 30, no. 2, pp. 102-106, 2016.

[49] C. Q. Xu, D. Z. Zhao, B. Y. Yuan et al., "Differential game model on joint carbon emission reduction and low-carbon promotion in supply chains," Journal of Management Sciences in China, vol. 19, no. 2, pp. 53-65, 2016.

[50] M. Laroche, J. Bergeron, and G. Barbaro-Forleo, "Targeting consumers who are willing to pay more for environmentally friendly products," Journal of Consumer Marketing, vol. 18, no. 6, pp. 503-520, 2001.

[51] F. E. Ouardighi and K. Kogan, "Dynamic conformance and design quality in a supply chain: an assessment of contracts' coordinating power," Annals of Operations Research, vol. 211, no. 1, pp. 137-166, 2013.

[52] F. E. Ouardighi, "Supply quality management with optimal wholesale price and revenue sharing contracts: a two-stage game approach," International Journal of Production Economics, vol. 156, no. 5, pp. 260-268, 2014. 